\title{
Consideraciones sobre el patrimonio minero desde la perspectiva de un servicio geológico nacional
}

\author{
Mining heritage considerations from the standpoint of a national geological survey \\ CARMEN MARCHÁN, ALEJANDRO SÁNCHEZ.
}

Instituto Geológico y Minero de España (IGME) - c.marchan@igme.es - alejandro@igme.es

\begin{abstract}
Resumen
Se examina el concepto de patrimonio minero como materia de estudio para diversas especialidades de la arqueología, la historia y la etnografía. Se hace una sucinta revisión de los elementos constitutivos de este patrimonio y su posible puesta en valor, con fines científicos, didácticos y turísticos. Por otro lado, se analiza la importancia de la labor de apoyo que pueden brindar los servicios geológicos nacionales, a la variada gama de entidades comprometidas en la preservación de dicho patrimonio. Se exponen algunas ideas y dos manuales sobre métodos de identificación y valoración de sus posibles elementos constitutivos. Finalmente, se revisan las principales organizaciones internacionales, de ámbitos diversos, que contemplan entre sus cometidos la protección del patrimonio minero.
\end{abstract}

Palabras clave: Organismos internacionales; patrimonio minero; servicios geológicos; valoración; valorización.

\begin{abstract}
We examine the concept of mining heritage from the archaeological, historical and ethnographic point of view. We also make a brief review of the elements which constitute this patrimony and their potential assessment, for scientific, educational or tourist purposes. Moreover, we look at the support provided by national geological surveys to the varied range of organizations involved in the preservation of mining heritage. Several ideas and two manuals about identification methods, analysis and assessment of potential mining heritage sites are also explained. Lastly, we review the main international organizations from several fields, which include mining heritage protection as one of their scopes.
\end{abstract}

Key words: Assessment; geological surveys, international organizations; mining heritage; valuation.

\section{INTRODUCCIÓN}

\subsection{Definición}

El concepto de patrimonio histórico minero comprende a todos los vestigios de las actividades mineras del pasado, reciente o lejano, a las que un grupo social atribuye valores históricos, culturales o sociales (Puche Riart et al. 1994). Es decir, puede tratarse tanto de estructuras muebles e inmuebles, como de objetos, documentos y elementos inmateriales. De este enunciado tan generalista se deduce que los elementos constitutivos del patrimonio minero pueden formar parte del patrimonio histórico, arqueológico, industrial, paisajístico cultural, etnográfico o incluso geológico y por lo tanto pueden ser objeto de estudio para la arqueología, la historia de la tecnología, la historia económica y la historia social (Sánchez, 2011).

\subsection{Valor histórico y social}

En la segunda mitad del siglo XIX, cuando los avances tecnológicos aportados por la primera revolución industrial permitieron la intensificación y profundización de las explotaciones, se despertó el interés por los restos de utensilios y artefactos, de edad incierta, descubiertos a medida que se recuperaban labores antiguas y que se incorporaban a las colecciones museísticas, puesto que en aquella época la geología, la arqueología y la prehistoria se consideraban disciplinas científicas muy afines.

Hasta los años 60 del siglo XX la noción de patrimonio histórico minero aludía a los restos de las explotaciones mineras de los periodos preindustrial y protoindustrial, es decir anteriores a la primera revolución industrial, y se circunscribía casi exclusivamente al campo de la arqueología (Figura 1). Conviene recordar que la primera revolución industrial aportó a la minería la máquina de vapor y otros ingenios complementarios que facilitaron enormemente, entre otras, las tareas del desagüe y del transporte y al mismo tiempo las instalaciones se volvieron más complejas. De esta manera el patrimonio minero pasa a ser considerado como una subdivisión del patrimonio industrial (Guiollard, 2005). 


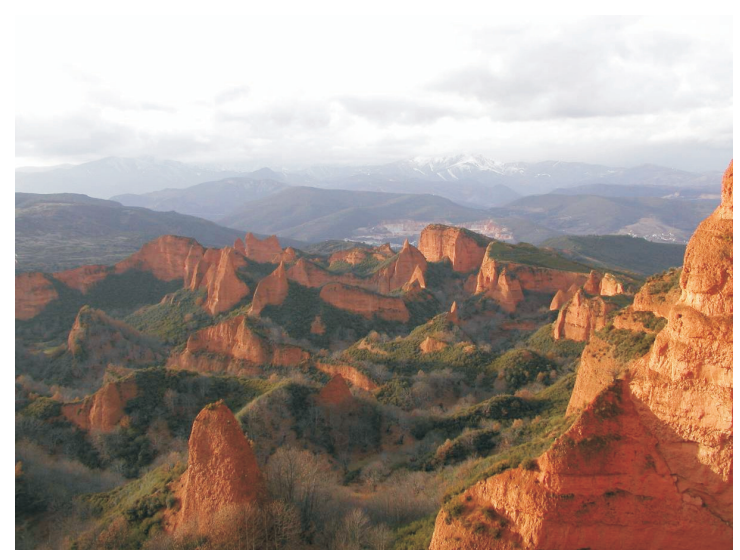

Figura 1 - Minas romanas de oro. Las Médulas (España). Patrimonio arqueológico.

A partir de esos años se inició el desarrollo de la arqueología industrial, como una nueva especialidad de la historia, y del patrimonio industrial, como concepto derivado (Parejo, 2010), en el que se abría la posibilidad de incluir aquellas explotaciones mineras de la época contemporánea, que reuniesen determinados valores. En las explotaciones mineras de largo recorrido histórico, los restos del periodo industrial se encuentran frecuentemente superpuestos a los de etapas previas. Su valor histórico, en este caso, puede proceder de la doble consideración de los vestigios arqueológicos y de los restos calificables como patrimonio industrial (Figura 2).

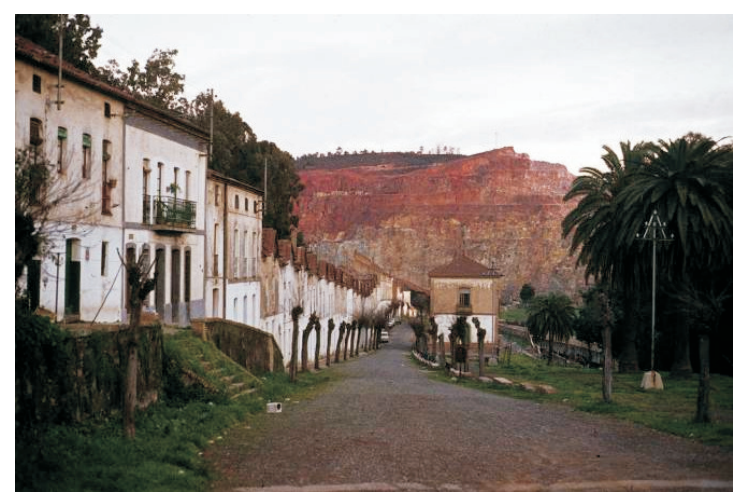

Figura 2 - Minas de Río Tinto (España). Patrimonio industrial minero superpuesto.

En ámbitos regionales y locales, el patrimonio minero de época contemporánea significa la memoria física de un pasado, y su recuperación, el restablecimiento de los vínculos que existieron entre los habitantes de la zona y los recursos minerales de su subsuelo.

Pero igualmente puede conllevar las opiniones negativas respecto a la minería, como actividad industrial explotadora de los trabajadores, contaminante del medio ambiente y destructora del paisaje.
Tras el cierre y abandono de las explotaciones de un distrito minero, entre la población asentada suele producirse una toma de posiciones antagónicas: solamente los que allí trabajaron se sienten partícipes de la cultura minera y manifiestan un orgullo de clase profesional y entre el resto de la población, por el contrario, se incrementan las actitudes desfavorables hacia el pasado minero, considerándolo como algo ominoso. Tras el transcurso de dos o más generaciones, las posiciones contrarias se matizan, por lo general, y renace el interés por recuperar la memoria y los vestigios de aquel pasado.

\section{ELEMENTOS CONSTITUTIVOS DEL PATRIMONIO MINERO}

La explotación de las minas tiene algunas peculiaridades respecto a otras ramas de la industria. Su ubicación está condicionada por la del yacimiento mineral y esto, aunque parezca una obviedad, determina el carácter autosuficiente de un buen número de instalaciones mineras en regiones apartadas, sobre todo en el pasado, hasta tal punto que además de las instalaciones directamente relacionadas con el laboreo y el beneficio de los minerales, se les dota de un amplio panel de instalaciones auxiliares, urbanizaciones, infraestructuras de transporte, plantas de energía, etcétera.

El propio desarrollo de la explotación comporta una evolución continua de los tajos, desde su apertura hasta el cierre definitivo, y la adaptación, modificación o destrucción de las instalaciones ante los avances técnicos. Los yacimientos se explotan hasta su agotamiento o hasta su pérdida de rentabilidad, quedando las labores, instalaciones e infraestructuras abandonadas y arruinadas, y así ha sido al menos hasta la denominada era ecológica.

El resultado es un heterogéneo conjunto de elementos susceptibles de constituir un legado patrimonial de la minería (Pérez de Perceval Verde, 2010), clasificables, tal y como se expone en la introducción, en elementos inmuebles y muebles, documentos, herencia inmaterial y paisaje cultural. Veamos, de forma sucinta, los elementos que pueden incluirse en cada una de estas categorías:

\subsection{Patrimonio inmueble}

En el patrimonio inmueble se incluyen habitualmente instalaciones de grandes dimensiones que sin embargo, en determinadas circunstancias, son susceptibles de traslado y reubicación, como son las estructuras metálicas, o de madera, para carga y transporte (Figuras 3, 4, 5). 


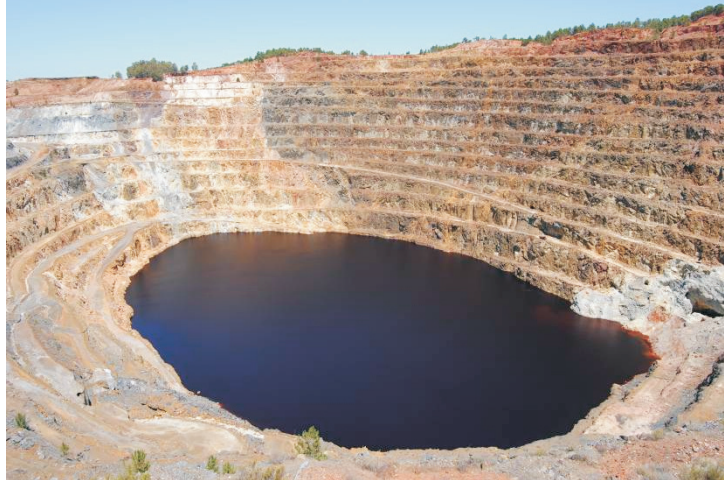

Figura 3-Corta Atalaya, minas de Río Tinto (España).

- Labores y obras, subterráneas y a cielo abierto.

- Instalaciones y edificaciones para las operaciones de arranque, carga, transporte vertical y transporte horizontal, en la plaza de la mina.

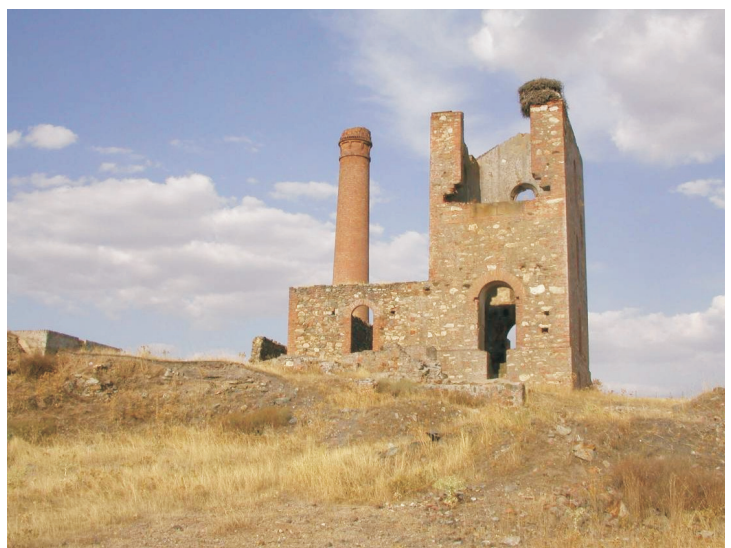

Figura 4 - Casa de máquinas tipo Cornish, mina Santa Catalina, Berlanga (Badajoz, España).

- Instalaciones y edificaciones para la generación de energía.

- Instalaciones mineralúrgicas, metalúrgicas y siderúrgicas, plantas químicas y edificaciones anexas.

- Edificios administrativos.

- Urbanizaciones y edificaciones auxiliares de carácter social.

- Escombreras y escoriales.

- Infraestructuras, instalaciones y edificaciones para el transporte en la periferia de la plaza.
- Infraestructuras, instalaciones y edificaciones para la carga en la periferia de la plaza.

- Infraestructuras hidráulicas.

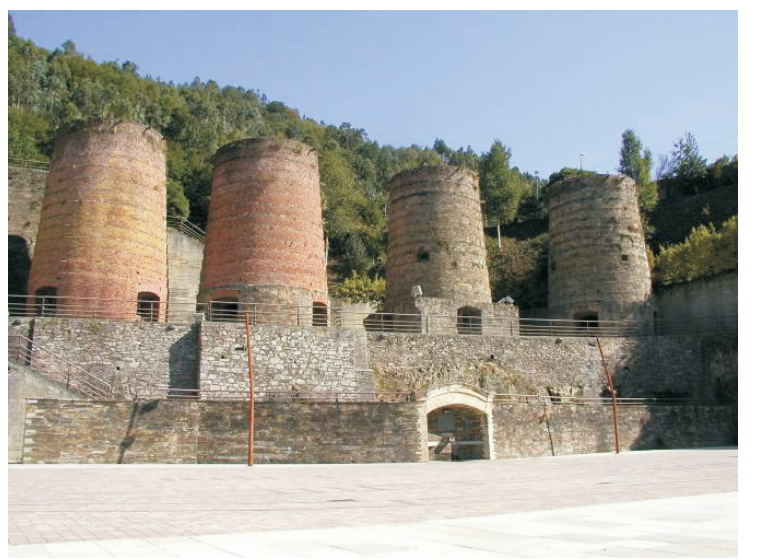

Figura 5-Hornos de reducción, Pontenova (Lugo, España).

\subsection{Patrimonio mueble}

La lista de los elementos muebles puede ser inacabable y contener tanto a las máquinas específicas de las operaciones mineras como a otras de uso más extendido, herramientas manuales propias del trabajo minero, sistemas de iluminación, sistemas de protección e incluso utensilios domésticos, documentos particulares, fotografías y películas (Figuras 6, 7). Un elemento documental de características singulares lo constituyen los testigos de los sondeos, ordenados y clasificados.

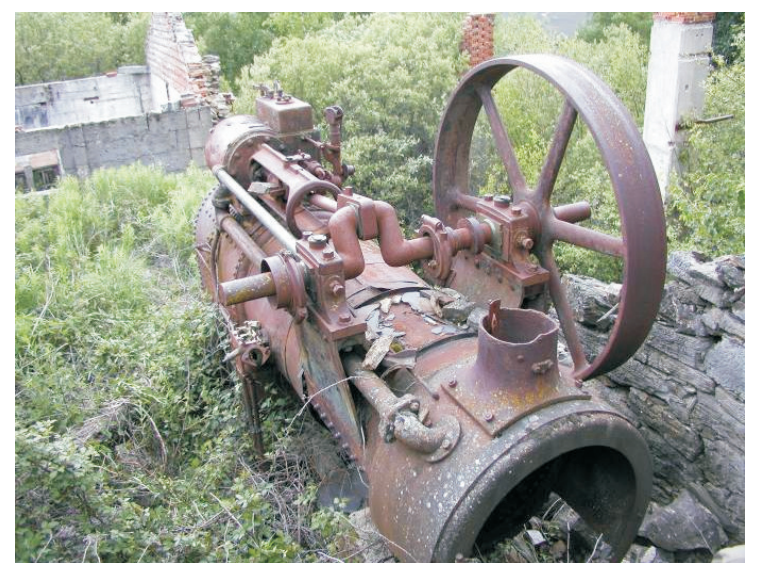

Figura 6 - Máquina de vapor locomóvil, minas de Vilanova (Orense, España). 


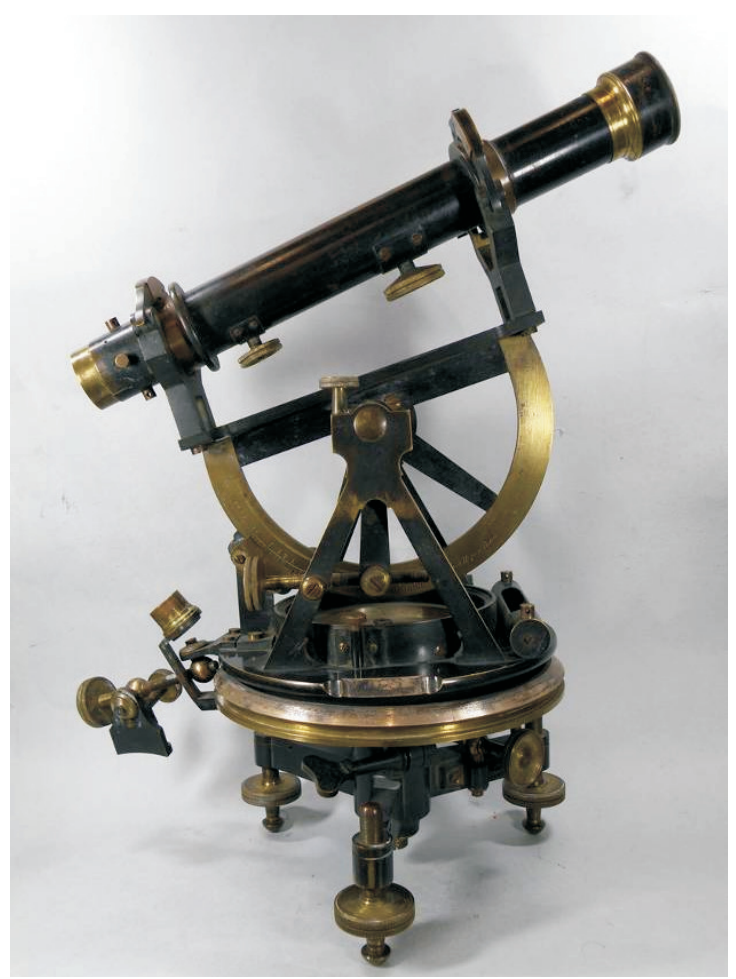

Figura 7 - Teodolito. Museo Geominero. Instituto Geológico y Minero de España.

\subsection{Archivos documentales}

Por lo común se trata de documentos del periodo industrial, porque los de épocas anteriores, si existieran, deberían encontrarse en los archivos históricos nacionales. Constituyen la memoria de las compañías y son un elemento esencial para el estudio de la historia de las explotaciones abandonadas y de la evolución de las cuencas y distritos (Pérez de Perceval Verde, 2010). Sin embargo, su fragilidad intrínseca, incluso durante las etapas de actividad de las empresas, los hace a menudo irrecuperables (Guiollard, 2005). De ordinario, la documentación se distribuye en tres o cuatro secciones, tales como: dirección, administración, técnica y comercial (Figura 8).

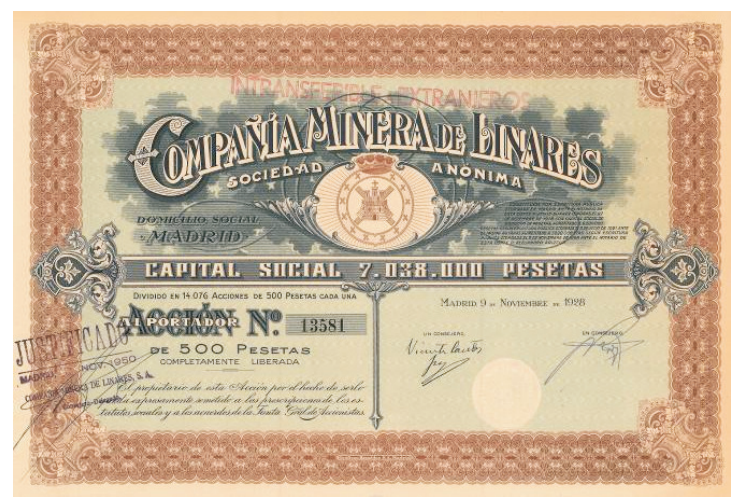

Figura 8 - Acción de la Compañía Minera de Linares. Archivo histórico de la Sociedad Minero Metalúrgica de Peñarroya (S.S.M.Peñarroya)-España (IGME).

\subsection{Patrimonio inmaterial}

Constituido por la superposición de elementos sociales, económicos y culturales a lo largo de los diversos periodos de actividad de las explotaciones. Igualmente, se incluyen la destreza en los diversos oficios propios del sector minero y su adaptación a las innovaciones de la técnica y la memoria viva de la vida cotidiana y de la actividad laboral en los diversos estamentos de las compañías. Se puede hablar de una cultura minera como simbiosis de las actividades meramente productivas y de los usos, comportamientos sociales y folclore aportados por la mano de obra de muy diversa procedencia, cultura que puede permanecer tras el abandono de las explotaciones e incluso ser reivindicada por la población que ocupa actualmente los antiguos poblados mineros (Pérez de Perceval Verde, 2010) (Figura 9).

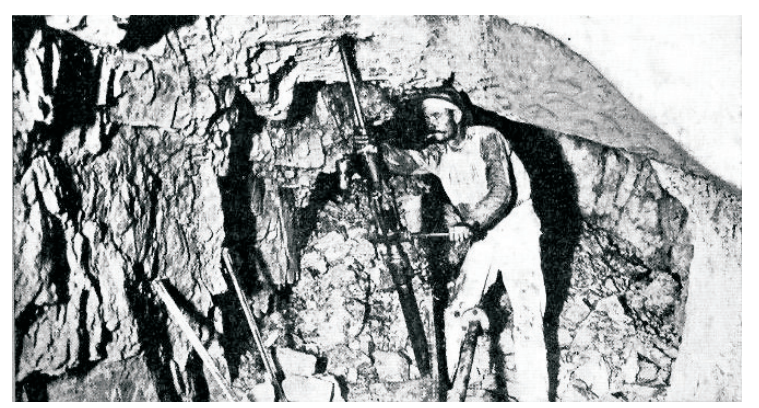

Figura 9 - Barrenero en la mina Los Guindos, 1936 (Jaén, España).

\subsection{Paisaje cultural minero}

Según la Convención del Patrimonio Mundial de la UNESCO, el paisaje cultural refleja la influencia del desarrollo de actividades humanas, de índole diversa, sobre un determinado territorio, interviniendo en él componentes naturales y culturales, tanto tangibles como intangibles (Figura 10). En nuestro caso, es el resultado de la interacción de las operaciones mineras con el medio natural y lo forman la combinación de los huecos de las explotaciones, las escombreras, y otros acopìos diversos, y los restos de las instalaciones, y construcciones, con las alteraciones morfológicas y geoquímicas del terreno derivadas de las explotaciones.

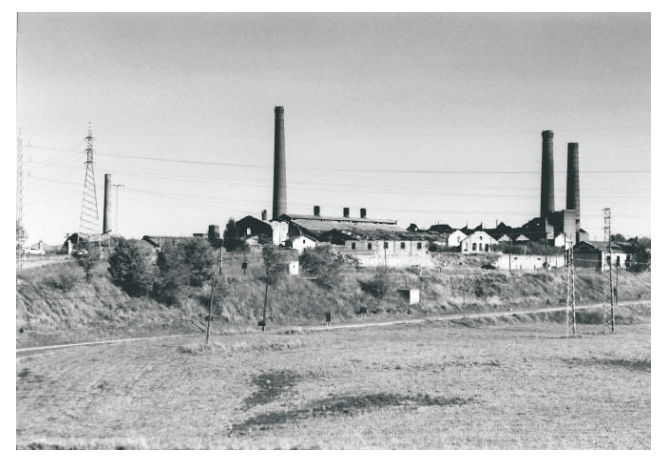

Figura 10 - El Cerco, Peñarroya (Córdoba, España). Paisaje cultural industrial y minero. 
Se trata del elemento patrimonial más controvertido, puesto que para los detractores de la minería es la constatación de la destrucción y perturbación del medio natural, provocadas por la explotación «desmedida» de los recursos geológicos. Sin embargo, el paisaje minero puede comportar un valor intrínseco cultural (IGME, 2012) e incluso aportar impactos positivos al medio, como el afloramiento de elementos del patrimonio geológico o la generación de nuevos ecosistemas en los huecos de las explotaciones y en las instalaciones abandonadas.

\section{VALORIZACIÓN DEL PATRIMONIO MINERO}

La valorización, como puesta en valor o incremento de valor, del patrimonio minero es la consecuencia del interés en recuperar el legado de la pasada actividad minera de una región, o de una localidad, promovido por iniciativas muy diversas y que surgió inicialmente, a finales de los años sesenta del pasado siglo, en los países desarrollados con una fuerte tradición minera.

Guiollard (2005) plantea cuatro cuestiones fundamentales, independientemente de la entidad que se proponga llevar a cabo esa tarea: ¿Por qué valorizar?, ¿quién valoriza?, ¿con qué objetivos? y ¿con qué medios?.

Las actuaciones más habituales, con objetivos científicos, didácticos o turísticos, se traducen en la creación de museos y archivos mineros, labores mineras inactivas visitables, parques mineros, paisajes culturales, espacios naturales con vestigios mineros, etcétera.

En situaciones de abandono reciente de las explotaciones, la valorización del patrimonio puede constituir una posible alternativa, con la creación de empleos directos y desarrollo turístico, para resolver problemas de tipo socioeconómico, pero es fundamental planificar los proyectos teniendo presente las características de la población residente y sus inquietudes sociales y económicas (Pérez de Perceval Verde, 2010).

La puesta en valor de una antigua explotación minera, o de un grupo de explotaciones, no puede ser una intervención aislada, sino un proyecto que precisa definición y análisis para un plazo medio-largo, no sólo para evitar el fracaso económico, sino igualmente los daños que pudieran ocasionarse a los vestigios que se pretendía proteger (Sánchez, 2011).

\section{EL PATRIMONIO MINERO EN EL ÁMBITO DE LOS SERVICIOS GEOLÓGICOS NACIONALES}

Entre las misiones que tienen encomendadas la mayor parte de los servicios geológicos nacionales, bien que adaptadas a las circunstancias de cada país, figuran las de crear una infraestructura de conocimiento en el ámbito de las ciencias y las tecnologías de la Tierra y prestar asistencia técnico-científica, e informar, en ese ámbito, a las entidades públicas, privadas y a la sociedad en general. Por otra parte, los servicios geológicos cuentan con fondos documentales en los que está recogida buena parte de la información generada en el estudio de los yacimientos minerales del territorio nacional, por la propia administración estatal y por los titulares de derechos mineros.

Los estudios sobre los vestigios mineros de los periodos preindustrial y protoindustrial se enmarcan de forma mayoritaria, como ya hemos dicho, en el campo de la arqueología, constituyendo una especialización que desde sus inicios ha sabido utilizar la información infraestructural que, de ordinario, proporciona un servicio geológico. Por el contrario, las actuaciones para preservar y valorizar el patrimonio minero industrial parten de iniciativas promovidas desde una gama muy amplia de entidades, desde asociaciones locales de los propios habitantes de los distritos mineros, hasta organismos de las diversas administraciones estatales, pasando por entidades culturales de ámbito diverso, incluso dentro del "amateurismo», y por último desde las propias compañías mineras. Y salvo en ese último caso, por lo general se aprecia una exigüidad en las propuestas de los aspectos científicos y técnicos de la geología y la minería. Así, los datos históricos, sociales, tecnológicos o económicos se presentan desvinculados de la caracterización del yacimiento, aun tratándose de un recurso geológico sobre el que generaciones pasadas desarrollaron una industria.

Por lo tanto, vemos la necesidad de contar con el apoyo de una institución técnica experta en la investigación, gestión y aprovechamiento de los recursos minerales y con amplios conocimientos sobre la geología y la metalogenia del país, que desarrolle un programa encaminado a estudiar, inventariar y valorar el patrimonio minero, a instancias tanto de las administraciones estatales como de otras entidades y asociaciones (Féraud et al., 2001). De esta manera se proporciona a la sociedad, en general, una información de carácter infraestructural indispensable a la hora de llevar a cabo investigaciones científicas acerca del pasado económico, social y tecnológico de un determinado distrito minero, así como para cualquier tipo de programa de actividades didácticas o turísticas relacionadas con el medio natural.

Evidentemente, la colaboración de un servicio geológico nacional no puede extenderse al estudio de todas las categorías de elementos patrimoniales expuestas más arriba. Las competencias están muy claras en el caso de los elementos inmuebles, una buena parte de los muebles, los documentos y los componentes antrópicos del paisaje cultural minero.

Por otra parte, conviene incidir en determinados aspectos de la protección de elementos del legado minero en los que esta colaboración es fundamental: el rescate y la conservación de los archivos 
documentales, ante su abandono por parte de las propias compañías, y la preservación ocasional, por representar algún valor científico, didáctico o turístico, de labores mineras abandonadas frente a las disposiciones legales de seguridad minera, que obligarían a su destrucción.

En el primer caso, los servicios geológicos cuentan con probada experiencia en la gestión de sus archivos de documentación geológica-minera y más aún teniendo en cuenta la casi certeza de que ya existan datos, en esos archivos, sobre las minas abandonadas que se pretende valorar, puesto que la mayor parte de las legislaciones mineras nacionales atribuyen a los servicios geológicos la misión de receptores de la información generada en los trabajos de investigación desarrollados por las empresas públicas o privadas, sobre las distintas categorías de derechos mineros.

En la hipotética situación de que un proyecto de valorización, con la aquiescencia del organismo de cultura pertinente, aconsejara respetar determinadas labores mineras que por imperativos de seguridad debieran estar destruidas y cegadas, el servicio geológico nacional puede jugar el papel de mediador legal y técnico, entre las administraciones y las entidades promotoras del estudio (Féraud. et al., 2001).

\section{IDENTIFICACIÓN Y VALORACIÓN DEL PATRIMONIO MINERO}

Parafraseando a Luis Carcavilla en su formulación sobre el patrimonio geológico (Carcavilla et al., 2007), podemos decir que cualquier resto de una actividad minera no es, a priori, patrimonio minero.

La calificación y la valoración de los vestigios de las explotaciones como integrantes de un patrimonio minero comportan habitualmente una fuerte carga de subjetividad, y además no es fácil separar los criterios de identificación de los de valoración. La identificación de un elemento ya comporta una valoración, a priori. El atribuir valor patrimonial a una determinada explotación minera puede ser fruto de una opinión generalizada, de un grupo de ámbito regional o local, o de un investigador independiente (Pearson \& McGowan, 2000).

Dada la gran variedad tipológica de los elementos susceptibles de ser clasificados como integrantes de un patrimonio minero inmueble, es aconsejable llevar a cabo la valoración por un panel de expertos que, al menos, comprenda las siguientes especialidades: minería, historia de la tecnología, arqueología, arquitectura, metalurgia y geografía.

A día de hoy, no existe unanimidad, ni tan siquiera a un nivel primordial, en el procedimiento para abordar la identificación y valoración de los diversos elementos del patrimonio minero, ni tampoco se dispone de suficiente información publicada al respecto.

De lo que conocemos, vamos a exponer de forma resumida la guía del Instituto Geológico y Minero de España (IGME) y a hacer una breve referencia a los manuales del Australian Council of National Trusts and Australian Heritage Commission.

En la normativa del IGME (IGME, 2009, 2012), para identificar y valorar el patrimonio minero, se recomienda un planteamiento interdisciplinario, que recoge técnicas de la exploración minera y de la prospección arqueológica. De la primera toma el procedimiento utilizado habitualmente en la descripción de las características del yacimiento mineral, las labores mineras que sirvieron para su explotación, así como las instalaciones anejas. De la prospección arqueológica, sigue el método del reconocimiento superficial, sin remoción del terreno, para tratar de interpretar las funciones de las estructuras visibles.

En cada distrito se hace una selección previa de los indicios de interés potencial, mediante encuestas entre los conocedores de la zona y análisis de la documentación existente. El estudio de cada enclave comporta una nueva revisión de la documentación y un reconocimiento sobre el terreno. Todos los datos quedarán reseñados en una ficha-informe ad hoc, que además contendrá las conclusiones sobre la valoración preliminar de los restos examinados.

Para la fase de valoración se establecen unos valores intrínsecos y de uso. Inicialmente las características se puntúan de 0 a 4 y por el carácter subjetivo de la calificación, como ya se ha indicado, lo recomendable es la valoración múltiple promediada, por un grupo de expertos.

Los intrínsecos se distribuyen según tres criterios o aspectos, que pueden presentarse tanto aislados como combinados: arqueológico industrial, arqueológico e histórico, y paisajístico cultural (tabla 1). Además de esos tres valores intrínsecos se considera un factor de vulnerabilidad.

El valor de uso representa la posible rentabilidad económica y social derivada de la utilización, del bien de que se trate, con fines científicos, didácticos y recreativos o turísticos, de forma independiente o combinada. 
Tabla I - Valores intrínsecos

\begin{tabular}{|c|c|c|}
\hline Valor & Elementos & Características a valorar \\
\hline $\begin{array}{l}\text { Arqueológico } \\
\text { industrial }\end{array}$ & $\begin{array}{l}\text { Labores } \\
\text { Instalaciones y edificaciones de la plaza } \\
\text { Instalaciones y edificaciones de la } \\
\text { periferia }\end{array}$ & $\begin{array}{l}\text { Estado de conservación }{ }^{1} \\
\text { Grado de conocimiento científico previo }^{2} \\
\text { Representatividad }^{3} \\
\text { Relevancia tecnológica }^{4} \\
\text { Relevancia arquitectónica }^{5} \\
\text { Singularidad }^{6} \\
\text { Relevancia histórica, económica y social }^{7}\end{array}$ \\
\hline $\begin{array}{l}\text { Histórico y } \\
\text { arqueológico }\end{array}$ & $\begin{array}{l}\text { Labores } \\
\text { Instalaciones y edificaciones de la plaza } \\
\text { Instalaciones y edificaciones de la } \\
\text { periferia }\end{array}$ & $\begin{array}{l}\text { Estado de conservación } \\
\text { Grado de conocimiento científico previo } \\
\text { Representatividad } \\
\text { Relevancia tecnológica } \\
\text { Relevancia arquitectónica } \\
\text { Singularidad } \\
\text { Relevancia histórica, económica y social } \\
\text { Relación con yacimientos arqueológicos }\end{array}$ \\
\hline Paisajístico cultural & $\begin{array}{l}\text { Impactos visuales positivos de labores, } \\
\text { instalaciones y edificaciones }\end{array}$ & $\begin{array}{l}\text { Grado de transformación }{ }^{9} \\
\text { Grado de evolución }^{10} \\
\text { Extensión }^{11} \\
\text { Espectacularidad o belleza }^{12}\end{array}$ \\
\hline
\end{tabular}

${ }^{1}$ Se refiere a su estado en el momento de llevar a cabo los reconocimientos sobre el terreno.

${ }^{2}$ Indica si los restos han sido objeto de estudios científicos y su alcance.

${ }^{3}$ Informa sobre la calidad como arquetipo del elemento en cuestión.

${ }^{4}$ Informa sobre el grado de innovación y eficiencia que pudieron alcanzar las labores e instalaciones de las que aún quedan restos.

${ }^{5}$ Informa sobre la singularidad constructiva o representatividad de un género arquitectónico en las instalaciones y edificios y anexos.

${ }^{6}$ Informa sobre las circunstancias que permiten clasificar a uno o más de los diversos restos como peculiares o poco frecuentes, a escala nacional o regional.

${ }^{7}$ Informa sobre la importancia histórica, económica y social que pudieron tener, a cualquier escala territorial, las explotaciones, los materiales extraídos y sus usos.

${ }^{8}$ Informa sobre la posible relación con yacimientos arqueológicos, situados en un radio predeterminado, en los que aparezcan vestigios de actividades mineras y metalúrgicas.

${ }^{9}$ Se refiere al estado final tras el cierre o abandono de la explotación o explotaciones.

${ }^{10}$ Se refiere al estado actual por implantación de actividades ajenas a la minería.

${ }^{11}$ Admite una valoración doble. Por un lado se puede considerar la extensión como un valor intrínseco del paisaje y por otro la vulnerabilidad disminuye en razón inversa a la extensión.

${ }^{12}$ De las alteraciones morfológicas generadas por las actividades mineras.

El «Mining Heritage Places Assessment Manual» se editó en 2000 (Pearson \& McGowan), tras unas publicaciones previas iniciadas en 1995, con el objetivo de facilitar el registro, análisis y valoración de enclaves de posible patrimonio minero. Está organizado con una estructura sencilla, de tal manera que pueda ser utilizado por personas no expertas en minería o en patrimonio, y que sin embargo puedan tomar decisiones básicas sobre valores patrimoniales.

Se compone de seis guías, las tres primeras son para el registro, análisis, identificación y valoración de los elementos que puedan considerarse patrimonio minero, dentro de cada complejo minero. Las otras tres contienen ayudas e informaciones complementarias. Además se incluye un apéndice con información sobre las tipologías y las morfologías de yacimientos minerales más frecuentes en Australia.

\section{EL PATRIMONIO MINERO Y LAS ORGANIZACIONES INTERNACIONALES}

Las organizaciones internacionales del ámbito de la cultura comenzaron a tomar conciencia, a finales de los años 60 del pasado siglo, de la necesidad de preservar los restos de instalaciones industriales abandonadas que pudieran tener un valor histórico, tecnológico o científico.

\subsection{Unión Europea}

El marco normativo europeo en materia de patrimonio industrial se limita a un conjunto de recomendaciones (Rec), propuestas metodológicas y códigos de buenas prácticas encaminadas a su identificación, protección, conservación y difusión, entre 
las que podemos destacar: la $\operatorname{Rec}(1979) 872$, relativa a la arqueología industrial; la dedicada a las ciudades industriales europeas, orientada a la revitalización de zonas tradicionalmente industriales y en declive, $\operatorname{Rec}(1987) 24$ y la relativa a la protección y a la conservación del patrimonio técnico, industrial y de obras de arte en Europa, en la que se pone de manifiesto la especificidad del patrimonio industrial y el propósito de su protección y conservación, proponiendo a los países miembros la realización de inventarios y la adopción de medidas jurídicas protectoras, $\operatorname{Rec}(1990) 20$.

Además de estas recomendaciones, la Unión Europea ha promovido numerosos programas de financiación para la puesta en valor y conservación del patrimonio industrial; entre ellos, podemos destacar:

- El programa de Itinerarios Culturales en el que se inscribe la «Ruta del hierro» en los Pirineos (2004) que conecta distintos asentamientos a lo largo de un recorrido transfronterizo vinculado a la explotación de dicho metal. Dentro del mismo programa se encuentra también el proyecto sobre la "Ruta del wolframio. Memoria de los Hombres y Patrimonio Industrial"(2012).

- Dentro de los Programas Interreg, financiados con fondos FEDER se están llevando a cabo proyectos de patrimonio minero como fue el proyecto Green Mines, cuya segunda fase es el proyecto ATLANTERRA (20102013), sobre puesta en valor de puntos de interés minero en la Zona Atlántica Europea.

- El programa Central Europe, también de la Unión Europea, promueve la cooperación entre países de la Europa Central para mejorar la innovación, accesibilidad y el medio ambiente, y aumentar la competitividad y atractivo de sus ciudades y regiones. El objetivo principal del grupo de trabajo es reunir conceptos sostenibles de uso innovador del patrimonio cultural tras el cierre de minas (Resource-CE.EU, 2013).

Por último, hay que mencionar el Convenio Europeo del Paisaje (Florencia, 20 de octubre de 2000) auspiciado por el Consejo de Europa y ratificado por España el 26 de noviembre de 2007, que constituye un punto de referencia para la consideración del espacio minero como paisaje cultural. La Estrategia Territorial Europea (ETE) incluye los paisajes culturales como integrantes del patrimonio cultural de la Unión Europea, y los considera un factor económico de importancia creciente para el desarrollo sostenible. Actualmente se está llevando a cabo un Plan Nacional de Paisajes Culturales para el período 2012-2016 con el objeto de salvaguardar aquellos más relevantes.

\subsection{Unesco}

La UNESCO reconoce el valor del patrimonio industrial con la incorporación a la lista de Lugares Patrimonio de la Humanidad de numerosos restos industriales, muchos de ellos derivados de actividades mineras y metalúrgicas. Es necesario destacar que la UNESCO asigna al concepto de patrimonio industrial un significado extenso al no establecer límites cronológicos.

El Consejo Internacional de Monumentos y Sitios Histórico-Artísticos (ICOMOS), fundado en 1965, en Polonia, es la única organización internacional no gubernamental cuyo cometido es promover la teoría, metodología y tecnología aplicadas a la conservación, realce y apreciación de los monumentos, los conjuntos y los referidos sitios. Como tal, forma parte del Comité de Patrimonio Mundial.

En 1981 se estableció la red ICOMOS-ICOMUNESCO, creándose la base de datos bibliográficos "ICOMOS» y la conexión directa con la UNESCO.

Por otra parte, el Comité Internacional para la Conservación del Patrimonio Industrial (TICCIH), es la organización mundial encargada del patrimonio industrial y como tal es asesor especial de ICOMOS en cuestiones de dicho patrimonio. Es precisamente en la Carta de Nizhny Tagil, resultado del XII Congreso Internacional $\mathrm{TICCIH}$, en 2003, donde se concretan exactamente las definiciones de patrimonio industrial y arqueología industrial. También se establece el periodo histórico en el que se puede hablar de patrimonio industrial, que se extiende desde el principio de la Revolución Industrial, la segunda mitad del siglo XVIII, hasta la actualidad, si bien se estudian sus raíces preindustriales y protoindustriales anteriores.

La UNESCO auspicia también la Red Global de Geoparques. El patrimonio minero ha servido, en algunos casos, como criterio fundamental para la declaración de geoparques en Europa, como es el caso de Copper Coast (Irlanda) y Rocca di Cerere (Sicilia) y el Parque Geológico y Minero de Cerdeña, ambos en Italia.

Otros organismos: Con objetivos o fines ligados a la geología y la minería, pero que también incluyen líneas de actuación relacionadas con el patrimonio minero: conservación, rehabilitación, puesta en valor para un desarrollo sostenible:

Los servicios geológicos nacionales, individualmente y dentro de la organización Eurogeosurveys (The Geological Surveys of Europe) que agrupa a 33 de ellos, entre sus objetivos tienen el de preservar el patrimonio minero como parte de la evolución cultural en Europa, así como promover el desarrollo de instalaciones, lugares y exposiciones que mejoren el conocimiento y valoración de la minería, la exploración minera y la geología, en tanto contribuyen al turismo y al potencial económico.

El patrimonio minero supone un registro de parte de nuestra historia cultural y tecnológica; proporciona la oportunidad de gran variedad de experiencias educativas y puede jugar un importante papel dentro del turismo cultural, lo que contribuye al 
desarrollo de las economías locales.

Así mismo, la Asociación europea de industrias mineras, menas metálicas y minerales industriales (EUROMINES), que funciona como red para la cooperación e intercambio de información del sector en Europa y con la comunidad minera mundial, realiza actuaciones sobre el papel que la recuperación del patrimonio minero puede suponer para el desarrollo regional (Euromines, 2013).

Finalmente, debe mencionarse el Programa Iberoamericano de Ciencia y Tecnología para el Desarrollo (CYTED), que trata de impulsar la recuperación y reutilización de las zonas mineras tras el cese de la actividad extractiva, articulando políticas y estrategias para la protección del medio ambiente, con una planificación y gestión del territorio que deberá incluir aquéllas que abordan la protección del patrimonio minero.

Entre sus objetivos específicos está: «En el caso de sitios mineros de valor patrimonial promover la puesta en valor de su legado y la instalación de usos culturales (de turismo cultural de patrimonio minero) y educativos, como factor que contribuya a dinamizar la economía, al mismo tiempo que preservar la identidad local».

\section{CONSIDERACIONES FINALES}

La protección y el estudio del patrimonio minero, tanto si se refiere a una rama del patrimonio industrial, como al que se considera patrimonio histórico o arqueológico, es hoy día una cuestión de creciente interés en ámbitos geográficos y sociales muy diversos.

Los servicios geológicos nacionales, expertos en la exploración y explotación de los recursos minerales pueden desempeñar una labor importante como asesores de las múltiples entidades que se ocupan del patrimonio minero. Pero también es aconsejable que adquieran un papel más activo que el de simples consultores $\mathrm{y}$, aprovechando su experiencia, medios humanos y técnicos, aborden programas de inventario del patrimonio minero de los principales distritos del país.

Otra cuestión de capital importancia, en la que los servicios geológicos deberían tener más protagonismo, es la recuperación, ordenación y puesta en consulta de los archivos históricos de las compañías mineras extinguidas.

En lo que concierne a la metodología, o más bien a su ausencia, parece recomendable que las diversas asociaciones o federaciones continentales de servicios geológicos consideraran este asunto en alguna de sus comisiones, con el propósito de adoptar unas normas básicas, o guía general, para la identificación y valoración de este patrimonio. Pueden contribuir a alcanzar acuerdos las recomendaciones y programas de las diversas organizaciones internacionales, del ámbito de la cultura, la minería y la geología, que incluyen entre sus cometidos la protección del patrimonio minero.

\section{Referencias}

CARCAVILLA, L., LÓPEZ-MARTÍNEZ, J. and DURÁN, J.J. 2007. Patrimonio geológico y geodiversidad: investigación, conservación, gestión y relación con los espacios naturales protegidos. Instituto Geológico y Minero de España. Serie Cuadernos del Museo Geominero, no 7. Madrid. 360 p.

FÉRAUD, J.; MARTINS, L.; PHILIPPON, J and BARGE, H. 2001. Les impératifs de valorisation économique et touristique du patrimoine représenté par d'anciens sites miniers: Le rôle des services géologiques européens auprès des archéologues. Congresso Internacional sobre Patrimonio Geológico e Mineiro, Beja, Portugal. $11 \mathrm{p}$.

GUIOLLARD, P.C. 2005. Conservation et valorisation du patrimoine minier contemporaine. Mines de charbon, d'or et d'uranium en France métropolitaine. Edition Pierre-Christian Guiollard. Z A Le Cherbois, France.117 p.

IGME, 2009. Patrimonio minero de Extremadura. Informe inédito. Madrid $619 \mathrm{p}$. At http://www.igme.es/internet

IGME, 2012. Guía metodológica para la integración del patrimonio minero en los procesos de evaluación de impacto ambiental. Informe inédito. Madrid 43 p. At http://www.igme.es/internet

PAREJO, A. 2010. El legado físico (e inmaterial) de la industrialización. ÁREAS. Revista Internacional de Ciencias Sociales. El patrimonio industrial, el legado material de la historia económica. 29. Ediciones de la Universidad de Murcia. Fundación Caja Murcia. Murcia, 11-18.

PEARSON, M. \& MCGOWAN, B. 2000. Mining Heritage Places. Assessment Manual. Australian Council of National Trusts and Australian Heritage Commission. At http://www.environment.gov.au/heritage. Camberra, $212 \mathrm{p}$.

PÉREZ de Perceval Verde, M.A. 2010. Patrimonio minero: un variopinto y problemático mundo de vestigios. ÁREAS. Revista Internacional de Ciencias Sociales. El patrimonio industrial, el legado material de la historia económica. 29. Ediciones de la Universidad de Murcia. Fundación Caja Murcia. Murcia, 51-59.

PUCHE Riart, O.; GARCÍA Cortés, Á. \& MATA Perelló, J.M. 1994.Conservación del patrimonio histórico minerometalúrgico español. IX Congreso Internacional de Minería y Metalurgia, Tomo 5. León, España, 433-448. 
SÁNCHEZ Rodríguez, A. 2011. Estudio del patrimonio minero de Extremadura. En P. Florido and I. Rábano (Eds.). Una visión multidisciplinar del patrimonio geológico y minero. Cuadernos del Museo Geominero, 12. Instituto Geológico y Minero de España, Madrid, 3-30.

EUROMINES, 2013. Sustaining and Promoting the Mining Heritage of Europe. Accessed March 6, 2013, at http://www.euromines.org

RESOURCE-CE.EU, 2013, Accessed April 4, 2013, at http://www.resource-ce.eu/en/links/relatedprojects-and-networks

RUTA del wolframio. Memoria de los Hombres y Patrimonio Industrial, 2012. Accesed July, 3, 2013, at http://www.routesofwolfram.eu/es 